\title{
Orofacial and Skeletal Manifestations of Hypophosphatemic Rickets in Fanconi Bickel Syndrome
}

\author{
Veena $\mathbf{R}^{1}$, Babitha. $\mathrm{K}^{2, *}$, Anuradha Pai ${ }^{3}$ \\ ${ }^{1}$ Reader in department of oral medicine \& radiology, The Oxford dental college, Bommanahalli, Hosur road, Bangalore 560068, \\ Karnataka, India \\ ${ }^{2}$ Post graduate student in department of oral medicine \& radiology, The Oxford dental college, Bommanahalli, Hosur road, Bangalore \\ 560068, Karnataka, India \\ ${ }^{3}$ Professor and head of the department of oral medicine \& radiology, The Oxford dental college, Bommanahalli, Hosur road, Bangalore \\ 560068, Karnataka, India \\ *Corresponding author: dr.babitha.k@gmail.com
}

Received January 08, 2014; Revised July 20, 2014; Accepted July 31, 2014

\begin{abstract}
Wide array of systemic disorders have their manifestations in oral cavity. These disorders can be mainly syndromic, metabolic or congenital diseases. The dental features in these disorders can be expressed on a wider latitude from mild to extensive forms. Here is an incidence of a case of hypophosphatemic rickets in Fanconi Bickel syndrome with multiple oral and general phenotypic features.
\end{abstract}

Keywords: Fanconi syndrome, hypophosphatemic rickets, oligodontia

Cite This Article: Veena R, Babitha. K, and Anuradha Pai, "Orofacial and Skeletal Manifestations of Hypophosphatemic Rickets in Fanconi Bickel Syndrome.” American Journal of Clinical Medicine Research, vol. 2, no. 4 (2014): 68-71. doi: 10.12691/ajcmr-2-4-1.

\section{Introduction}

Multiple missing teeth, mobility, delayed eruption are some of the signs and symptoms well appreciated in a dental setting. However, when these present together inappropriate to the patient's age, along with characteristic general physical features; this may create a high suspicion of underlying severe systemic disorder. A systematic and careful approach to such characteristic manifestations may guide a dentist in diagnosing rare conditions and their orofacial features. Such disorders may evoke special interest in the field of dentistry in discovering the unknown dental anomalies.

\section{Case Report}

A 17-year-old adolescent male came to our out-patient department with a chief complaint of multiple missing teeth in his oral cavity since many years. Adding to the above complaint, patient's parent revealed that they did not observe normal shedding and eruption of subsequent teeth in their child in comparison to the elder sibling. Also permanent teeth which erupted late in time were found mobile in a short span of time.

Since the patient presented with distinct physical characteristics for his age, on interrogation, the parent revealed that the patient was suffering from a medical illness and was under management for the same. However, they failed to provide us the details of his illness. Also they reported a history of delayed milestones. Patient's intelligence quotient was normal. Parents and elder sibling of the patient were normal. His parents had a consanguineous marriage.

On examination, the patient was asthenic and poorly nourished, had typical waddling gait, short statured with a height of $126 \mathrm{~cm}\left(<20^{\text {th }}\right.$ percentile for the age $)$ and weighed about $25 \mathrm{~kg}\left(<10^{\text {th }}\right.$ percentile for the age). Skeletal examination revealed deformed chest, rachitic rosary (beading of ribs), Harrison's sulcus, transverse sulcus, bowed hands and (genus valgum) knock knees. Widening of epiphyseal ends of wrist, elbows, and ankle joints were also noticed (Figure 1).

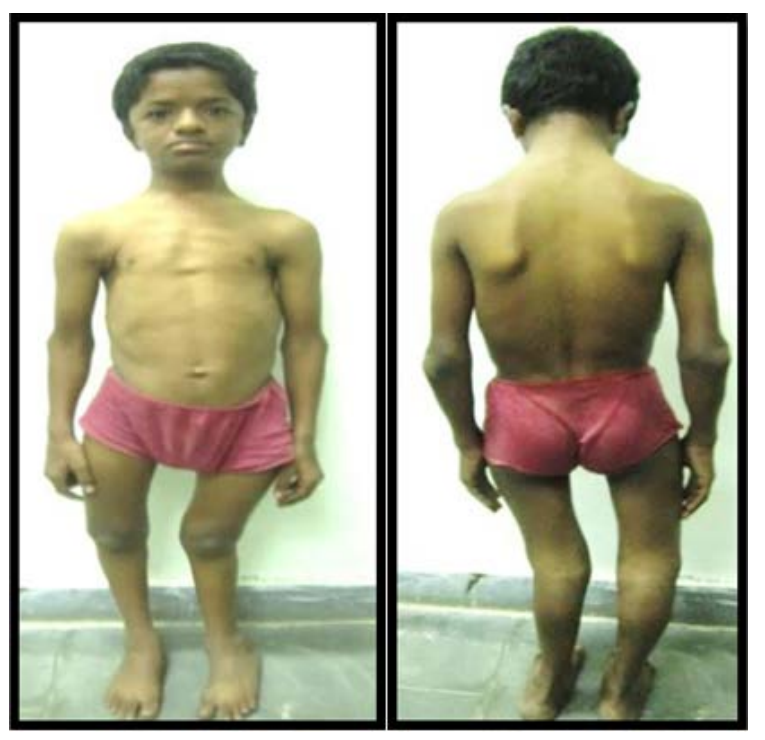

Figure 1a and 1b. Patient presenting with ricketic features 

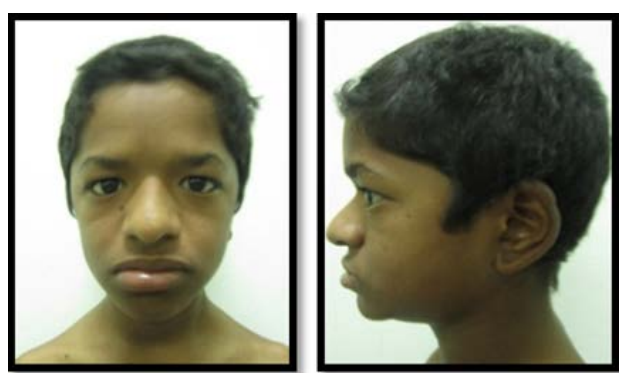

Figure 2a and 2b. Extra oral features

Extra oral examination revealed brachycephaly, hypertelorism, broad nose, mid face deficiency (Figure 2a and 2b). Intraorally multiple missing teeth with poorly formed alveolar ridges were noted. Grade 1 and grade 2 mobility was present in many teeth(Figure $3 \mathrm{a}$ and $3 \mathrm{~b}$ ).

Based on the skeletal findings, a provisional diagnosis of rickets with orodental manifestations was considered. Necessary investigations were advised and the patient was instructed to follow up with all the previous medical records before charting a treatment plan.

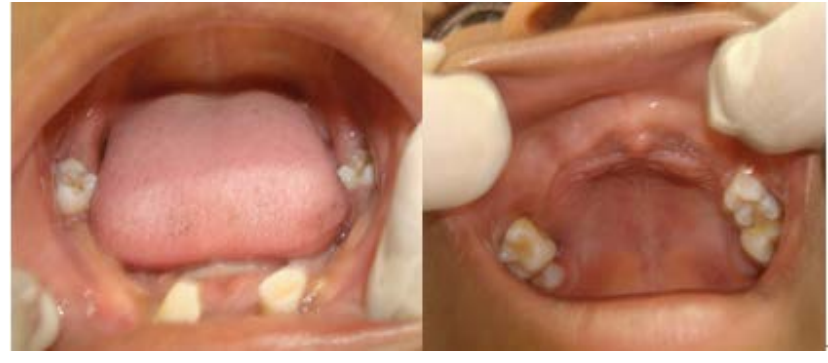

Figure 3a and $3 b$.

Orthopantomograph revealed reduced height of maxillary and mandibular alveolar ridges with multiple embedded teeth in both jaws. Incomplete root formation and open apex of embedded upper and lower premolars and molars were appreciated. Other findings included rarefying osteitis in relation to periapical region of lower left canine and taurodontism in upper left first molar (Figure 4). In addition to the above findings, lateral cephalogram revealed severely deficient maxilla and true skeletal class III malocclusion with open bite (Figure 5).

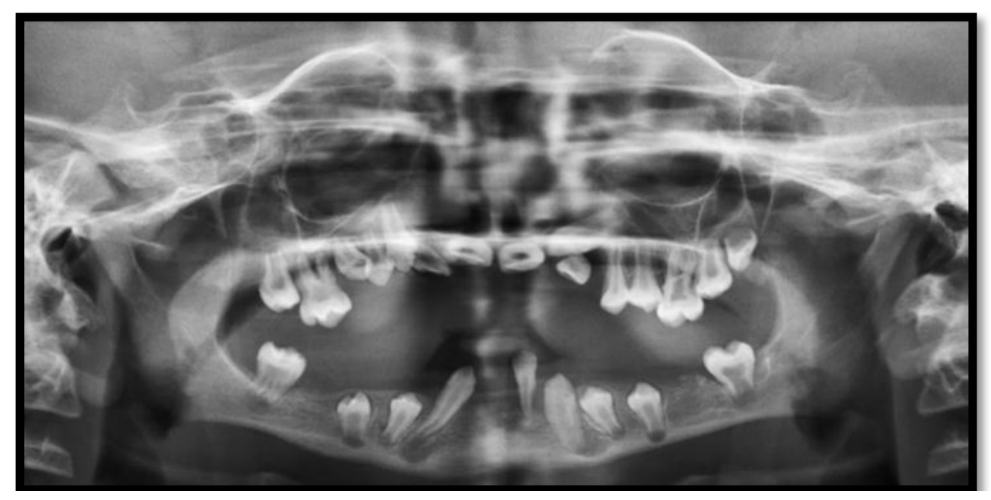

Figure 4. OPG revealing multiple dental anomalies

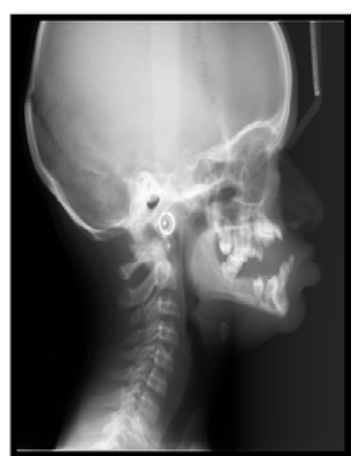

Figure 5. Lateral cephalogram reveals class III malocclusion and midface deficiency

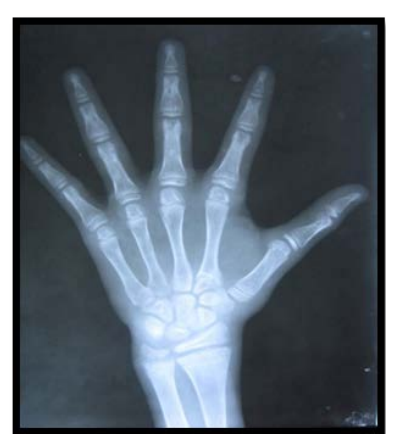

Figure 6. Hand wrist radiograph showing indicators of delayed skeletal development
Hand wrist radiograph examination showed the absence of sesamoid bone in the proximal phalanx of $1^{\text {st }}$ digit and failure of fusion of epiphysis of proximal phalanx of $2^{\text {nd }}$ digit and middle phalanx of $3^{\text {rd }}$ digit (Figure 6). Knee radiograph revealed presence of radiopaque metal rods in femur and tibial bones suggestive of treated fractures (Figure 7).

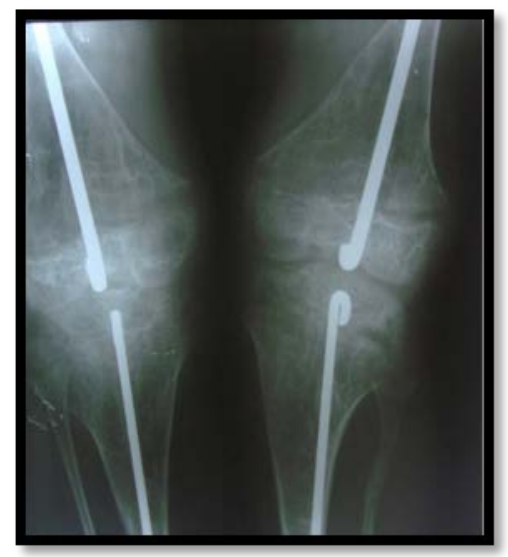

Figure 7. knee $\mathrm{X}$ ray shows treated fracture of left and right tibial bone.

During the patient's first followup his medical reports were assessed which revealed the following data. At the age of $2 \frac{1}{2}$ years, patient had problems of developmental delay, poor weight gain, polyuria, abdominal distension, 
skeletal deformities, and recurrent respiratory infections. Ricketic features like open anterior fontanelle, fiddle shaped chest, Harrison's sulcus, rachitic rosary, cat's back, lateral bowing of fore-arms and legs; and glycogen storage disorder signs like protuberant abdomen with soft palpable liver was present. He was diagnosed to have FBS in his childhood and since then has been on treatment with neutral phosphate solution, calcirol granules and alkali solution. Childhood history of treated case of fractured leg was also present. His present biochemical reports of serum electrolytes, calcium and phosphates, urine and serum creatinine were within normal limits.

Thus with the childhood illness reports, clinical signs and symptoms and radiological investigations, we came to the final diagnosis of oral manifestations of hypophosphatemic rickets in FBS. The oral manifestations included all the features listed in Table 1.

Table 1. clinical, radiologic and histological dental findings in our patient

\begin{tabular}{|c|} 
patient \\
\hline ORAL FINDINGS: \\
1. Multiple clinically missing teeth \\
2. Class III malocclusion \\
3. Mobility of teeth \\
4. Pseudoanodontia \\
5. Spontaneous dental abscess \\
6. Taurodontism \\
7. Reduced height of alveolar ridges \\
8. Incomplete root formation \\
9. Multiple embedded teeth \\
10. Interglobular dentin on histopathology
\end{tabular}

The patient is currently under the medical management of alkali solution, calcirol granules and neutral phosphate solution.

Dental management: Our patient was counseled and educated on the maintenance of good oral hygiene. He underwent a thorough oral prophylaxis. Mobile lower left lateral incisor was extracted and subjected to histopathological examination which revealed the presence of interglobular dentin. On subsequent visit, cusp tip of lower left canine was appreciated clinically at this age of 17 years. The patient at present is under regular follow up.

\section{Discussion}

Fanconi syndrome is a systemic, autosomal recessive, inherited syndrome usually resulting in proximal renal tubular acidosis (RTA), of which FBS is one of the entity. [1] FBS, has also been known as hepatorenal glycogenosis with renal Fanconi Syndrome and categorized under Glycogen Storage Disease Type XI represents an extremely rare disorder. [2] In 1949, Guido Fanconi and Horst Bickel described it for the first time. [2,3] According to Santer et al, a total of 109 cases in 88 families have been reported. [3,4,5] Reported cases are mainly from all parts of Europe, Turkey, Israel, Arabian countries of the Near East and North Africa, Japan, and North America. [2] Search in Pubmed for "oral manifestations of FBS" yielded a result of only one such reported case. Parental consanguinity was present in index case and the literature suggests its presence in 2/3rd of patients of FBS [4,5].

Features typical to FBS presents with variable degrees of manifestations of hypophosphatemic rickets, RTA, and hepatomegaly resulting from GSD XI. [6]
Hypophosphatemic rickets in Fanconi syndrome presents with failure of production of 1,25-dihydroxy vitamin D from its precursor 25-hydroxy vitamin $\mathrm{D}$ and defective resorption of phosphate in the proximal renal tubule. [7] This causes imbalance primarily in bone metabolism and forms the basis for all skeletal and dental morbid features. Its prevalence is approximately 1 in 20,000 [7]

Pathophysiology of FBS has been well explained in the previous articles [8,9] The underlying pathology of bone disease in FBS has been simplified and explained by two distinct mechanisms as shown in Figure $8[8,9]$.

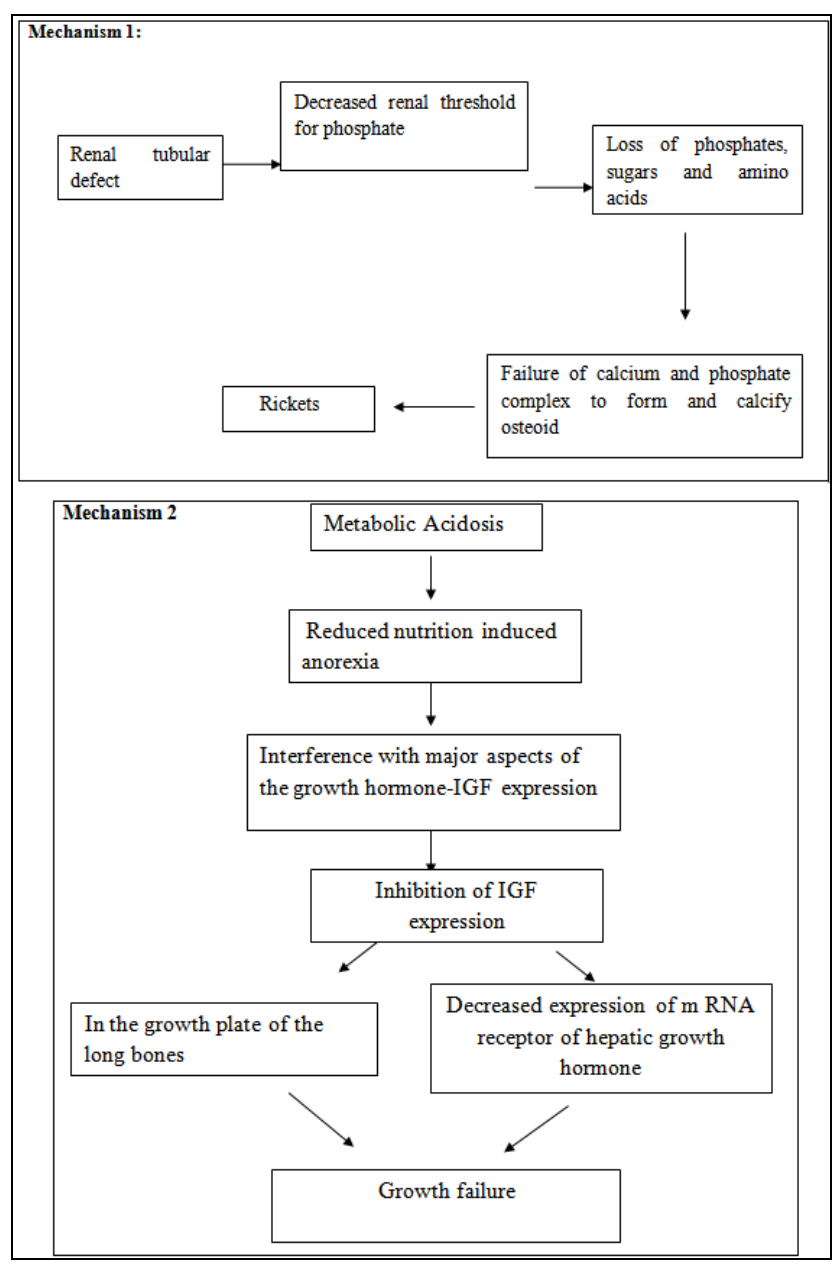

Figure 8. shows the flowchart explaining the pathophysiology of bone disease in rickets

Hypophosphatemia in FBS results in hypoplasia and deficient calcification of mineralized structures such as bones and teeth. Among various types of rickets, hypophosphatemic rickets presents mainly with dental manifestations. [10] The skeletal and dental manifestations of hypophosphatemic rickets have been enumerated in Table 2 and Table 3 [7,11,12].

Table 2. skeletal manifestations of hypophosphatemic rickets

\begin{tabular}{|c|c|}
\hline General manifestations & Index case \\
\hline Short stature & Present \\
\hline Chest deformities: pigeon chest, Harrison's sulcus & Present \\
\hline Genu valgum or varum & Genu varum \\
\hline $\begin{array}{c}\text { Widening of the ends of long bones like wrists ankle } \\
\text { and knees }\end{array}$ & Present \\
\hline $\begin{array}{c}\text { Long bones such as ribs, pelvis, and column are } \\
\text { predisposed to fractures }\end{array}$ & $\begin{array}{c}\text { Fracture of } \\
\text { tibia }\end{array}$ \\
\hline
\end{tabular}


Table 3. Dental manifeatations of hypophosphatemic rickets DENTAL FINDINGS

\begin{tabular}{|c|}
\hline DENTAL FINDINGS \\
\hline CLINICAL FINDINGS : \\
Poorly formed alveolar ridges \\
Delayed eruption \\
Multiple missing teeth \\
Clinically normal teeth \\
RADIOLOGICAL FINDINGS \\
Hypoplastic alveolar ridges \\
Taurodont, \\
Delayed tooth development \\
Enlarged pulp spaces and chambers and high pulp horns. \\
Spontaneous dental abscesses in clinically normal teeth \\
HISTOLOFICAL FINDINGS \\
Thin hypoplastic and hypocalcified enamel \\
dentin in circumpulpal dentin, dentinal clefts \\
Dentin dysplasia
\end{tabular}

Craniofacial features and various dental abnormalities helps the oral physician to discover underlying systemic disease/ syndrome.. Some of the oral/dental and characteristic skeletal features has been described in the Table 4. [13,14,15] Knowledge of such presentations helps in early diagnosis and management of systemic disease /syndrome thus reducing the morbidity of disease and improving the quality of life.

Table 4. Few differential diagnosis simulating the orofacial and skeletal manifestations similar to the present case

\begin{tabular}{|c|c|}
\hline $\begin{array}{c}\text { SYNDROME } \\
{[14,15,16]}\end{array}$ & FEATURES \\
\hline $\begin{array}{c}\text { Osteogenesis } \\
\text { imperfecta }\end{array}$ & $\begin{array}{c}\text { Autosomal dominant; Very short stature, triangular } \\
\text { face, severe scoliosis, blue sclera, dentinogenesis } \\
\text { imperfecta }\end{array}$ \\
\hline $\begin{array}{c}\text { Autosomal bone disorder } \\
\text { dysplasia }\end{array}$ & $\begin{array}{c}\text { Clavicular aplasia/hypoplasia, persistently open skull } \\
\text { sutures, macrocephaly, brachycephaly, } \\
\text { hypertelorism, a depressed nasal bridge, midfacial } \\
\text { hypoplasia, supernumerary teeth, narrow high arched } \\
\text { palate, delayed tooth eruption, enamel hypoplasia a } \\
\text { long neck, narrow thorax, conductive deafness, } \\
\text { scoliosis }\end{array}$ \\
\hline Achondroplasia & $\begin{array}{c}\text { Disproportionate short stature, lordotic lumbar spine, } \\
\text { a trident hand configureuration, limitation of elbow } \\
\text { extension, rhizomelic shortening of the arms and } \\
\text { legs, prominent buttocks and a protuberant abdomen } \\
\text { Craniofacial features include enlarged calvarium } \\
\text { with hydrocephaly, brachycephaly, midfacial } \\
\text { hypoplasia, low nasal bridge, prominent forehead } \\
\text { and dental malocclusions. }\end{array}$ \\
\hline
\end{tabular}

Overall prognosis for survival to adulthood in our patient seems to be favorable; Literature reveals at least three more patients of FBS to have reached adulthood in stable condition [2].

Dental considerations: Preventive dental care including counseling and educating the patient on importance of maintenance of good oral hygiene, periodic dental examinations, topical fluoride applications, and pit and fissure sealants should be advised. [10] Dental morbidity in the patient can be managed by oral rehabilitation. This includes a multidisciplinary approach involving the orthodontist, prosthodontist and speech therapist in order to facilitate speech, mastication, and esthetics.

Conclusion: Early diagnosis and management of this category of patients is of upmost importance to minimize the extent of morbidity. Although our patient was diagnosed with Fanconi Bickel syndrome at the age of 2.5 years and has been under meticulous medical management, he presented with severe skeletal and dental manifestations. However, the patient has been able to lead a near normal life of 17 years.

\section{References}

[1] Golembiewska E and Ciechanowski K. Renal tubular acidosisunderrated problem? Acta biochimica polonica. 2012; 59 (2).

[2] Deshpande P and Ali U. Primary Fanconi Syndrome. Indian pediatrics 1997; 34: 547-49.

[3] Setoodeh A and Rabbani A. Transient Neonatal Diabetes as a Presentation of Fanconi- Bickel Syndrome. Acta Medica Iranica 2012; 50 (12) 837

[4] Hadipour F et al. Fanconi syndrome versus osteogenesis imperfecta: An Iranian case with novel gene mutation in glucose transporter 2 gene and review of literature. Indian journal of human genetics. 2013; 19 (1): 84-86.

[5] Şimşek E, et al Case report: A novel mutation of the GLUT2 gene in a Turkish patient with Fanconi-Bickel syndrome The Turkish Journal of Pediatrics 2009; 51: 166-168.

[6] Jagtap s v. et al. review: Hypophosphatemic rickets. Indian journal of endocrinology and metabolism. 2012; 16 (2) 177-182.

[7] Puneet Batra, Zahra Tejani, Michael Mars, X-Linked hypophosphatemia: Dental and histologic findings J Can Dent Assoc 2006; 72 (1): 69-72.

[8] Savelli PD et al: Fanconi syndrome. Metabolic studies on treatment. The Journal of bone and joint surgery. 1955; 37 (4) 529-539.

[9] James C.M. Chan, Jon I. Scheinman, Karl S. Roth Renal Tubular Acidosis. Pediatrics in Review Vol.22 No.8 August 2001. 277-87.

[10] Tümen et al. Types of Rickets, Dental and Histologic Findings: Review of the Literature. Pesq Bras Odontoped Clin Integr, João Pessoa 20099 (2): 241-246

[11] Pereira et al Dental Alterations Associated with X-Linked hypophosphatemic rickets. Journal of Endodontics 2004; 30 (4) 241-45.

[12] Aysun Avsar: Dental findings in a child with glycogen storage disease type IA. Quintessence international 2007 ; 37: e36-e40

[13] Antieevie D et al,osteogenesis imperfecta: A current overview of musculskeletal radiology and new genetic concepts. Acta Clin Croat 2002; 41 (Suppl): 101-111.

[14] Ravi Prakash S. Mohan. Cleidocranial dysplasia: Clinic radiological illustration of a rare case Journal of Oral Science, Vol. 52, No. 1, 161-166, 2010.

[15] Smriti Rohilla Case report: Orofacial manifestations of achondroplasia EXCLI Journal 2012; 11: 538-542. 